\title{
Awareness about reproductive health, contraceptive methods, STDs including HIV/AIDS, and HPV vaccine, among adolescent girls in district Faridkot in Punjab
}

\author{
Seema Grover ${ }^{*}$, Nishi Garg${ }^{1}$, Rupali², Balpreet Kaur ${ }^{1}$
}

${ }^{1}$ Department of Obstetrics and Gynecology, ${ }^{2}$ Department of Preventive and Social Medicine, Guru Gobind Singh Medical College, Faridkot, Punjab, India

Received: 05 March 2017

Accepted: 01 April 2017

\section{*Correspondence:}

Dr. Seema Grover,

E-mail: groverseema4@gmail.com

Copyright: $\odot$ the author(s), publisher and licensee Medip Academy. This is an open-access article distributed under the terms of the Creative Commons Attribution Non-Commercial License, which permits unrestricted non-commercial use, distribution, and reproduction in any medium, provided the original work is properly cited.

\begin{abstract}
Background: Adolescents are more vulnerable than adults to unplanned pregnancies and sexually transmitted diseases including HIV/AIDS. Female adolescents have a higher risk of contracting an STD than their male counterparts. Hence creating awareness in them about reproductive health is the need of the hour.

Methods: This was a cross sectional school based Study which was conducted in various schools of Faridkot city of Punjab where 400 Adolescent girls of class 11th and 12th age between 16-19 years, studying in English medium schools in district Faridkot through predesigned multiple choice questionnaires.

Results: In our study, most of the girls (67\%) were not aware about the meaning of reproductive health. Amongst contraceptive methods, $62.5 \%$ knew about condoms. The awareness about STDs was highest about HIV/AIDS $(70.75 \%)$ and low (less than $20 \%$ ) for other STDs. They also scored low about symptoms and route of transmission of STD's. Only 17\% of the girls knew about HPV vaccine. Attitude towards sex education was positive.

Conclusions: Poor knowledge in girls about Reproductive Health and STDs (other than HIV/AIDS) is of serious concern. Therefore, education about reproductive health should be incorporated in the curriculum which should be given through teaching, interpersonal communication, television, health camps and specialist.
\end{abstract}

Keywords: Acquired immunodeficiency syndrome, Human immunodeficiency virus, Human papilloma virus, Sexually transmitted diseases

\section{INTRODUCTION}

Adolescence is a period of dynamic transition and it is a very sensitive period. The World health organization (WHO) defines "adolescent" as an individual between 10 to 19 years of age. According to UNICEF, there are 243 million adolescents comprising $20 \%$ of the total population of India. ${ }^{1}$

Reproductive health is an important component of general health, it sets the stage for health beyond the reproductive years and affects the health of the next generation. Adolescence is a period of increased risktaking and therefore susceptibility to behavioural problem at the time of puberty and new concern about reproductive health. ${ }^{2}$

Adolescents are more vulnerable than adults to unplanned pregnancies and sexually transmitted diseases including HIV/AIDS. Majority of adolescents still do not have access to information and education on sexuality, reproduction, and sexual and reproductive health and rights, nor do they have access to preventive and curative service. $^{3}$ 
Consistent with the economic and social changes in the country, girls in India are increasingly marrying late with a subsequent increase in the age at first childbirth. This has made the risk of premarital sex higher than ever before.

The problem with most STDs is that they can occur symptom-free and can thus be passed on unaware during unprotected sexual intercourse. On an individual level, complications can include pelvic inflammatory diseases and possibly lead to ectopic pregnancies and infertility. ${ }^{4}$ Female adolescents are likely to have a higher risk of contracting an STD than their male counterparts as their partners are generally older and hence more likely to be infected. ${ }^{5,6}$ The risk is higher for female adolescents as their cervical anatomic development is incomplete and especially vulnerable to infection by certain sexually transmitted pathogens. ${ }^{7}$

Many diseases can occur by lack of awareness, myths, hence there is need for creating awareness among these vulnerable groups. ${ }^{8}$ Adolescent girls also lack adequate knowledge about sexual matter and contraception which results in early pregnancy, maternal morbidity and mortality and unsafe abortions. ${ }^{9}$

Twenty seven percent of adolescent mothers have reported an unmet need for contraception. Nearly $35 \%$ of HIV infections occur among the young people in the age group of $15-34$ years. ${ }^{10}$

Knowledge about contraception is important for young students as un-planned pregnancies can be prevented and dire consequences of unsafe abortions and STDs could be avoided. ${ }^{11}$ The reproductive health needs of adolescents have long been neglected. In last decade, the importance of information on sexuality and reproduction is being increasingly emphasized. ${ }^{12}$

Our study was conducted to determine awareness and knowledge of adolescent girls about reproductive health, sexually transmitted diseases, (including HIV/AIDS and Human Papilloma virus), and also about contraception. The study was taken up keeping in mind that Faridkot is a small district with comprising more of rural $(65 \%)$ than urban population $(35 \%)$. Another reason for concern is the increase in drug addiction in the youth of this area which is very likely to increase the STD's. A survey in Punjab indicates existence of a large population of people who inject drugs (about 75,000 injecting drug users as opposed to about 25,000 in 2001).

This has serious implications for the HIV/AIDS programmed of the state. This study estimates that there are about 2.3 lakh opioid dependent people in Punjab. ${ }^{13}$ It has also been pointed out that in districts like Faridkot there are many cases where young men and their girlfriends become heroin addicts. ${ }^{14}$ So far, no study on this has been done on this topic in the state of Punjab. It is the need of the hour that the adolescents should be well informed on the health risks associated with sexual activity and on how to protect themselves and others. The results of our study can help point out areas where STD risk communication for school-attending adolescents needs to be improved. Education by health professionals can go a long way in improving the knowledge, perceptions and attitude of adolescent girls about reproductive health.

The objective of the study was to know the extent of awareness about reproductive health, contraception, STD's including HIV/AIDS and HPV among adolescent girls aged 16-19 years from district Faridkot. To provide basic information on safe sex, common problems related to reproductive health and prevention and of STDs including AIDS.

\section{METHODS}

A cross sectional study (observational) was carried out among 400 girl students who were between 16-19 years of age, using a structured predesigned multiple choice questionnaire.

After taking permission from the school authority, the class teachers of concerned class were explained the purpose of the study and rapport was built up with the girl students. Participation was voluntary and consent obtained from the willing students. Briefing was done to the students regarding the questionnaire provided to them. The age of the students was noted and the names were not being recorded.

A pre-tested, pre-coded, close-ended questionnaire was administered by authors themselves. Prior verbal consent was taken from the participants, their parents, and teachers for the study.

Anonymity was maintained by not including the names of the respondents in the questionnaire. After the questionnaire was filled, they were given a session of educational talk about the basics of reproductive health especially pertaining to their age group. The predesigned, pre-tested questionnaire included topics relating to reproductive health awareness, safe sex, contraception, HIV/AIDS and HPV vaccine. Data were entered and analyzed.

\section{RESULTS}

We enrolled 400 girls in this study, whose age was between 16-19 years.

They were in class $11^{\text {th }}$ and $12^{\text {th }}$ from different English medium schools of district Faridkot. The data collected from the questionnaires completed by the girls was tabulated and analysed as follows: Mean age of the girls enrolled in our study was found to be 17.2 years. 


\section{Knowledge of reproductive health}

In our study, we found that $67 \%$ of the girls were unaware about reproductive health, and only $33 \%$ were aware.

\section{Awareness of contraception and safe sex}

Amongst our study group, 283 girls out of 400 (70.75\%) of the adolescent girls knew that pregnancy can be prevented.

Table 1: Knowledge of contraceptive methods.

\begin{tabular}{|llllll|}
\hline Contraceptive method & Condom & Safe period & M/F sterilisation & Oral pills & IUCD \\
\hline $\mathrm{N}=400$ & 248 & 30 & 50 & 60 & 12 \\
\hline Percentage & $62 \%$ & $7.5 \%$ & $12.5 \%$ & $15 \%$ & $3 \%$ \\
\hline
\end{tabular}

\section{Knowledge of contraceptive methods}

In our study group, $62 \%$ girls were aware about condoms, $15 \%$ about OC pills, $7.5 \%$ about safe period and only $3 \%$ were aware about intrauterine device.

More than two methods of contraception were known to $23 \%$ of the girls (Table 1 ).

\section{Knowledge of safe sex}

Awareness about safe sex was present in $62.25 \%$ of the girls and the same girls also knew that condoms were important for safe sex.

Being a faithful partner was important for safe sex was known to $15.1 \%$ girls. Some girls $(12.2 \%)$ thought that use of OC pills was helpful. At least $28 \%$ of the study group did not any know about measures for safe sex.

\section{Awareness of STDs}

In our study 263 out of $400(65.75 \%)$ girls, said that they were aware about Sexually transmitted diseases and $35.25 \%$ answered in the negative.

\section{Symptoms of STDs}

The knowledge of symptoms was found to be poor. At least 165 girls out of $400(41.2 \%)$ knew none of the symptoms. Less than $20 \%$ of the girls had some knowledge of the symptoms of STDs. A small proportion 26 out of $400(6.5 \%)$ did not respond to this question, the likely reason could be that they had some vague or uncertain ideas (Table 2).

Table 2: Symptoms of STDs.

\begin{tabular}{|lllllll}
$\begin{array}{l}\text { Number } \\
\text { of girls }\end{array}$ & Vulval itching & $\begin{array}{l}\text { Boils/ulcers } \\
\text { on vulva }\end{array}$ & $\begin{array}{l}\text { Foul vaginal } \\
\text { discharge }\end{array}$ & $\begin{array}{l}\text { Pain during } \\
\text { intercourse }\end{array}$ & Do not know & No response \\
\hline N=400 & 75 & 48 & 54 & 62 & 165 & 26 \\
\hline Percentage & $18.7 \%$ & $12 \%$ & $13.5 \%$ & $15.5 \%$ & $41.2 \%$ & $6.5 \%$ \\
\hline
\end{tabular}

Table 3: Diseases considered as STDs.

\begin{tabular}{|lllllll|}
\hline Number of girls & HIV/AIDS & Gonorhea & Syphilis & Hepatitis B\&C & HIPV & No response \\
\hline $\mathrm{N}=400$ & 283 & 93 & 90 & 46 & 17 & 48 \\
\hline Percentage & $70.75 \%$ & $23.25 \%$ & $22.5 \%$ & $11.5 \%$ & $4.2 \%$ & $12 \%$ \\
\hline
\end{tabular}

\section{Diseases considered as STDs}

The awareness of the study group was highest about HIV/AIDS, which was $70.75 \%$, and low about other STD's, it being $23.25 \%$ for Gonorhea, $22.25 \%$ for Syphilis, $11.5 \%$ for hepatitis B and C, and only $6.5 \%$ for Chlamydia.

Some girls, $12 \%(48 / 400)$ did not answer to this question (Table 3).

\section{Routes of transmission of STDs}

More than half of the study group (53.75\%) were aware that Physical relation with infected partner was the route for transmission of STDs. Other routes were known to small proportions of girls; $7.25 \%$ were aware that use of dirty cloth during menses, and $5.25 \%$ were aware that abortion/ delivery by unskilled person can be a route of transmission. At least $47.25 \%$ of the girls had no idea about the route of transmission of STDs (Table 4). 
Table 4: Routes of transmission of STDs.

\begin{tabular}{|lll|}
\hline Route of transmission & $\begin{array}{l}\text { No. of girls } \\
\mathbf{n = 4 0 0}\end{array}$ & Percentage \\
\hline $\begin{array}{l}\text { Physical relation with } \\
\text { infected partner }\end{array}$ & 214 & $53.5 \%$ \\
\hline $\begin{array}{l}\text { Use of dirty clothes } \\
\text { during menses }\end{array}$ & 29 & $7.25 \%$ \\
\hline $\begin{array}{l}\text { Abortion/delivery by } \\
\text { unskilled person }\end{array}$ & 21 & $5.25 \%$ \\
\hline Do not know & 189 & $47.5 \%$ \\
\hline
\end{tabular}

\section{Awareness about HIV/AIDS}

In our study, $76.25 \%$ of the girls $(305 / 400)$ were aware about HIV/AIDS and only $23.75 \%$ (95/400) said that they were not aware.

\section{Routes of transmission of HIV/AIDS}

About the routes of transmission of HIV/AIDS, $56.25 \%$ knew that infected blood/needle can cause this, $49.75 \%$ knew unsafe sex as a route.

The vertical route of transmission (pregnant mother to child) was known only to $11 \%$, and a 17 out of 400 $(4.25 \%)$ girls gave no response. A small proportion $5.75 \%(23 / 400)$ carried the wrong impression that HIV/AIDS could be transmitted by Mosquito bite (Table 5).

\section{Sources of information about HIV/AIDS}

In our study, the most common mode of information among about HIV/AIDS was from teacher (62\%), followed by TV/Radio (29\%), print media (15.75\%), friends $(12.75 \%)$ and lastly family member (3\%) (Table $6)$.

Table 5: Routes of transmission of HIV/AIDS.

\begin{tabular}{|llllll|}
\hline No of girls & Unsafe sex & Infected blood /needle & Pregnant Mother to baby & Mlosquito bite & No Response \\
\hline 400 & 199 & 225 & 44 & 23 & 17 \\
\hline$\%$ age & $49.75 \%$ & $56.25 \%$ & $11 \%$ & $5.75 \%$ & $4.25 \%$ \\
\hline
\end{tabular}

Table 6: Sources of information about HIV/AIDS.

\begin{tabular}{|llllll|}
\hline Number of girls & Teacher & Television/Radio & Print media & Friend & Family member \\
\hline $\mathrm{N}=400$ & 248 & 116 & 63 & 51 & 12 \\
\hline Percentage & $62 \%$ & $29 \%$ & $15.75 \%$ & $12.75 \%$ & $3 \%$
\end{tabular}

\section{Awareness of HPV vaccine}

A majority of the girls in our study, $75.25 \%(301 / 400)$ had no idea about the HPV vaccine. Only $17 \%$ (68/400) were aware about this vaccine. A small proportion, $7.75 \%$ (31/400) did not respond to this question.

About the Role of HPV vaccine in women's reproductive health, $66.75 \%$ (267/400) admitted that they did not know about it. Prevention of cervical cancer was known to $17 \%$ (68/400) and $7.25 \%(29 / 400)$ said that it was used to prevent STD's, and 9\% of the girls (36/400) did not respond to this question.

\section{Attitude towards sex education}

In our study, $74.25 \%$ of the girls felt that sex education is necessary for adolescents, and only $23.75 \%$ replied in the negative. Only $2 \%$ of girls (8/400), gave no response.

\section{DISCUSSION}

Specific information regarding the level of knowledge related to reproductive and sexual health issues among adolescent girls of our area was collected, so as to target appropriate interventions among them. Mean age of girls in our study, was 17.2 years and it was comparable to mean age of 16.47 years in a study done in pre-university girls in Upupi, Karnataka. ${ }^{15}$ In our study only $44 \%$ of the adolescent girls were aware about reproductive health. Similar results $(43 \%)$ were found in a study done in Dhaka, Bangladesh. ${ }^{16}$

Lower levels of awareness (29.4\%) have been reported in a study done among Kurmi girls in Raipur, Chattisgarh. ${ }^{17}$

In the current study $70.75 \%$ girls were aware that pregnancy was preventable. Similar results were found by Patanwar and Sharma, where $64.5 \%$ had heard about contraception. ${ }^{17}$

Regarding the contraceptive methods, condoms were known to $62 \%$, OCP's to $15 \%$, sterilisation to $12.5 \%$, safe period to $7.5 \%$, and only $3 \%$ about intrauterine device. More than two methods were known to $23 \%$ of the girls.

In a college, based study among girls at Vishakapatnam, more than $50 \%$ were aware of Condoms and female sterilization. Knowledge regarding other methods was 
poor. ${ }^{11}$ In Haryana a study done in Rohtak found that at least two modes of contraception were known to $80.7 \%$ girls; OCP's and Copper-T were the most commonly known methods. ${ }^{18}$ A study done by Verma et al in Gujarat, (2011) has shown very poor awareness, only $10.8 \%$ girls were aware about one or the other method of contraception. ${ }^{19}$

In our study, $62.25 \%$ were aware about safe sex. The reason for this was in most schools there has been a compulsory class taken on HIV/AIDS in higher secondary classes in Panjab. Similar results were found by other authors in Dhaka Bangladesh, and in where 65\% subjects knew about safe sex. But in the study at Rohtak, only $11.3 \%$ of the girls knew correctly about safe sexual intercourse. ${ }^{16-18}$

In the current study, the awareness about STDs was high for HIV/AIDS, (70.75\%), and low about other STDs, like $23.25 \%$ for Gonorrhea, $22.25 \%$ for Syphilis, $11.5 \%$ for hepatitis B and C, and only $6.5 \%$ for Chlamydia. No response was given by $12 \%$ of the girls.

Similar results were found in Raipur, where most of the girls $(89.5 \%)$ were aware of HIV/AIDS but had poor awareness about Syphilis and Gonorrhea. ${ }^{17}$ The study at Vishakapatnam revealed that $84 \%$ of the subjects knew about HIV. In most high schools, teaching sessions have been taken for HIV/AIDS, hence it shows the effectiveness of intervention in the form of increased knowledge. Awareness was $16 \%, 12 \%$ and $2 \%$ for Candidiasis, syphilis and Gonorrhoea respectively. None were aware of chlamydial infections which are major causes of pelvic inflammatory diseases and tubal occlusions leading to infertility. ${ }^{11}$

In the study done in Dhaka, almost all the participants (98\%) knew about HIV/AIDS, 23\% about Syphilis, 17\% about Gonorrhea and $2 \%$ about Chancroid. ${ }^{16}$

As far as knowledge about sexually transmitted diseases is concerned, a good number $495(66.4 \%)$ heard about AIDS. Thanks to messages telecast on television, which was the main source of information on this topic. Other STDs known to girls were syphilis and gonorrhea (about $10 \%$ each). Most of the girls (78.5\%) knew that sexual transmission is the commonest mode of transmission of HIV, followed by infected needle, syringe and blood $(60.5 \%){ }^{19}$

The awareness about the symptoms of STDs was poor as $41.2 \%$ had no idea about the symptoms and less that $20 \%$ had some knowledge of the symptoms of STDs. Vulval itching was known to $18.7 \%$, dyspareunia to $15.5 \%$, foul vaginal discharge to $13.5 \%$ and ulcers on vulva to $12 \%$. About $6.5 \%$ girls did not respond to this question due to uncertain ideas.

In the Vishakapatnam study, 32\% of girls were aware of two or more symptoms of RTI. Itching over vulva (26\%), ulcers of vulva (35\%), lower abdominal pain (13\%), pain during intercourse $(11 \%)$, abnormal vaginal discharge (37\%), abnormal bleeding (17\%). ${ }^{11}$ Regarding symptoms of RTIs, in the present study one third knew of itching, boils and pain abdomen as symptoms Pratibha et al in reported awareness regarding these symptoms but number of students who knew about these were low. ${ }^{17}$

More than half of our study group (53.75\%) was aware that Physical relation with infected partner was the route for transmission of STD's. Other routes were less known, like use of dirty cloth during menses (7.25\%) and abortion/delivery by unskilled person (5.25\%). At least $47.25 \%$ of the girls had no idea about the route of transmission of STDs.

Our findings were similar to the findings of Vishakapatnam study, most known route was contact with infected partner (36\%) followed by usage of unclean cloth during menses $(20 \%){ }^{11}$ Patanwar and sharma in their study also reported this as the most commonly known methods of transmission (23.8\%) and (16.7\%) respectively, followed by unclean delivery place $(8.2 \%){ }^{17}$

In the study at Dhaka, Bangladesh Sexual intercourse was the most commonly identified route $(26 \%)$, followed by virus $(4 \%)$, bacteria (3\%). Majority in this group had no idea $(73 \%) .{ }^{16}$

In the present study, $76.25 \%$ of the girls were aware about HIV/AIDS. About the routes of transmission commonly known were infected blood/needle (56.25\%) and unsafe sex $(49.75 \%)$. The vertical route of transmission (pregnant mother to child) was known only to $11 \%$, and $(4.25 \%)$ girls gave no response. A small proportion $5.75 \%$ carried the wrong impression that HIV/AIDS could be transmitted by Mosquito bite.

Amongst the kurmi girls at Raipur, and also in Rohtak study around two thirds of the girls knew that sexual intercourse with an infected person and sharing needles for intravenous drug usage are the most common modes of transmission. ${ }^{17,18}$

In our study, the commonest mode of information among about HIV/AIDS was from teacher (62\%), followed by TV/Radio (29\%), print media, (15.75\%), friends $(12.75 \%)$ and lastly family member $(3 \%)$. In the study by Pratibha et al, Electronic media (TV/Media) was the most common source of information (71.6\%), followed by interpersonal communication $(24 \%)$ and then print media $(14.6 \%){ }^{17}$

Even in the college girls of Vishakapatnam, study, electronic media emerged as the most important source of information regarding HIV and contraception (television $65 \%$; radio $3 \%$ ) followed by print media (magazines $7 \%$; newspapers $18 \%$ ) and interpersonal communication (friends $23 \%$; teachers $8 \%$ and family members $(0.2 \%)$. 
Only $17 \%$ of the girls in our study knew about the HPV vaccine and were aware that it was meant for prevention of cervical cancer. In a study done in five metro cities it was found that $72 \%$ of them did not know about cervical cancer or HPV and $77.2 \%$ were not aware of the virus. ${ }^{20}$

In our study awareness was created about the vaccine and after explaining to the girls about the disease, more than $60 \%$ agreed to take the vaccine. Interventional programmed have shown to increase the awareness have a positive impact attitude of adolescents towards reproductive health. This has been shown by some studies within India and also in other developing countries like Turkey. ${ }^{21,22}$

In our study, $74.25 \%$ of the girls felt that sex education is necessary for adolescents. Patanwar and Sharma found in their study that $86.4 \%$ of the study group showed a positive attitude towards sex education. ${ }^{17}$

In Vishakapatnam study, $96 \%$ of the students thought that sex education was necessary and $56 \%$ felt that the appropriate age was 15 years. ${ }^{11}$

In The study in Bhavnagar, Gujarat, though the people in this part of state are more conservative, majority of the girls $(65.9 \%)$ wanted that sex education should be provided in the schools. ${ }^{19}$

\section{CONCLUSION}

Poor knowledge in girls about contraception, STD's (other than HIV/AIDS) and reproductive Health is a matter of serious concern. Reproductive health education should be incorporated in the curriculum of higher classes in all schools as it is the need of he hour and students are willing to learn. It should be given through teaching, interpersonal communication, television, and health session with a specialist.

\section{Recommendations}

Education on human sexuality with all the aspects, prevention and treatment of STDs and AIDS are a dire necessity among adolescent girls to help them reduce high risk behaviour to seek proper treatment of treatable ailments. All the students above 16 years of age should be taught about reproductive health, STD's and contraception, irrespective of whether they are enrolled as students of arts, commerce, Non-medical or Medical. Information on the human reproductive system and related issues on reproductive health need special attention and sensitization of teachers to "adolescent health care" is required.

\section{ACKNOWLEDGEMENTS}

Author would like to thank all the students, teachers and school authorities for their cooperation and participation in this study. I am grateful to Mr Baltej singh, Lecturer
Biostatistics in the Social and Preventive Medicine department of GGS Medical College, Faridkot, for his help in data tabulation and analysis as well as some valuable suggestions regarding the text of the study.

\section{Funding: No funding sources \\ Conflict of interest: None declared}

Ethical approval: The study was approved by the Institutional Ethics Committee

\section{REFERENCES}

1. UNICEF State of World's Children, 2011 Adolescence: an age of opportunity, p 1. Available from:

http://www.unicef.org/sowc2011/pdfs/India.pdf.

2. UNFPA. Guidelines on reproductive health, 1995. http//www.pierre@unfpa.Org,

http://www.Unescap.org, http:/www.ijppediatricsIndia,org.

3. Kotecha PV, Patel S, Baxi RK, Mazumdar VS, Misra $\mathrm{S}$, Modi E, et al. Reproductive health awareness among rural school going adolescents of Vadodara district. Indian J Sex Transm Dis. 2009;30:94-9.

4. MacDonald NE, Brunham R. The Effects of Undetected and Untreated Sexually Transmitted Diseases: Pelvic Inflammatory Disease and Ectopic Pregnancy in Canada. The Canadian Journal of Human Sexuality Special Issue: STDs and Sexual/Reproductive Health. 1997;6(2):161

5. Panchaud C, Singh S, Feivelson D, Darroch JE: Sexually transmitted diseases among adolescents in developed countries. Fam Plan Persp. 2000;32:2432.

6. Bozon M, Kontula O. Sexual initiation and gender in Europe. In Sexual behavior and HIV/AIDS in Europe. Edited by: M Hubert, $\mathrm{N}$ Bajos, and $\mathrm{T}$ Sandfort. London: UCL Press; 1998:37-67.

7. Berrington de González A, Sweetland S, Green J: Comparisons of risk factors for squamous cell and adenocarcinomas of the cervix: a meta-analysis. $\mathrm{Br} \mathrm{J}$ Cancer. 2004;90:1787-91.

8. Mahajan P, Sharma N. Awareness level of Adolescent Girls Regarding HIV/AIDS (A comparative study of rural and urban areas of Jammu). J Hum Ecol. 2004;17(4):313-4.

9. Bhan NB, Mahajan P, Sondhi M. Awareness Regarding Sex Knowledge among Adolescent Girls (16-20 years). Anthropologist 2004;6(2):101-3.

10. Implementation Guide On RCH-II Adolescent Reproductive Sexual Health Strategy. For State and District Health Managers. National Rural Health Mission.2006. Available from: http://www.mohfw.nic.in/NRHM/Documents/ARSH /Implementation_guide_on_RCH\%20II.pdf

11. Gollakota S, Mylavarapu RS, Padmavathi K. A Study of Awareness of Reproductive Health among College Students of Visakhapatnam and Padmavathi K. Journal of Dental and Medical Sciences. 2015;14(2)54-9. 
12. Kotwal N, Khan $\mathrm{N}$ and Kaul S. A review of the effectiveness of the interventions on Adolescent Reproductive Health in Developing countries, International Journal of Research and Publications. 2014;4(5):2250-3153.

13. Kumar R, Kumar M, Ambekar A, Rao R, Agrawal A and Mishra A. Punjab Opioid Dependence Survey: Brief Report; 2015.

14. Vaivasvat Venkat. This is how drug addiction is affecting entire families in Punjab. http://www.indiatimes.com/news/india/this-is-howdrug-addiction-is-affecting-entire-families-in-punjab254321.html

15. Rao RSP, Lena A, Nair NS, Kamath V, Kamath A. Effectivenss of reproductive health education among rural adolescent girls: A school based intervention study in Udupi Taluk, Karnatka. Indian J Med Sci. 2008;62:11.

16. Mou SZ, Bhuiya FA, Islam SM. Knowledge and perception of STD's, HIV/AIDS and reproductive health among female students in Dhaka, Bangladesh. Int Jamr. 2015;2(1):9-15.

17. Patanwar P, Sharma KKN. Awareness of reproductive health among the kurmi adolescent girls of Raipur city, Chhattisgarh, India. International Journal of Research in Health Sciences. 2013;19(3),2321-3251.

18. Mittal K, Goel MK. Knowledge regarding reproductive health among urban adolescent girls of
Haryana. Indian J Community Med. 2010;35(4):52930.

19. Verma PB, Bhalani KD, Pandya CM, Shah HM, Ramanuj VA and Singh MP. Reproductive health awareness and behavior of adolescent girls of Bhavnagar (Gujarat). Indian J. Prev. Soc. Med. 2011;42(1):5-8.

20. Ramavath KK, Olayi Roza. Knowledge and awareness of HPV infection and vaccination among urban adolescent girls in India: A cross sectional study. JOGI. 2013;63(6):399-404.

21. Dongre AR, Deshmukh PR, Garg BS.'The effect of community based health education intervention on management of menstrual hygiene among rural Indian adolescent girls'. World Health Population. 2007;9(3):48-54.

22. Ersin F. and Bahar Z. 'Effects of Training for Reproductive Health on Knowledge of Reproductive Health and Behavior in Adolescents'. International Journal of Caring Sciences. 2009;2(2):73.

Cite this article as: Grover S, Garg N, Rupali, Kaur B. Awareness about reproductive health, contraceptive methods, STDs including HIV/AIDS, and HPV vaccine, among adolescent girls in district Faridkot in Punjab. Int J Reprod Contracept Obstet Gynecol 2017;6:2003-9. 